\title{
Primary ventriculoperitoneal shunting outcomes: a multicentre clinical audit for shunt infection and its risk factors
}

\author{
Working Group on Neurosurgical Outcomes Monitoring; Peter YM Woo *, HT Wong, Jenny KS Pu, \\ WK Wong, Larry YW Wong, Michael WY Lee, KY Yam, WM Lui, WS Poon
}

\section{A B S T R A C T}

Objectives: To determine the frequency of primary ventriculoperitoneal shunt infection among patients treated at neurosurgical centres of the Hospital Authority and to identify underlying risk factors.

Methods: This multicentre historical cohort study included consecutive patients who underwent primary ventriculoperitoneal shunting at a Hospital Authority neurosurgery centre from 1 January 2009 to 31 December 2011. The primary endpoint was shunt infection, defined as: (1) the presence of cerebrospinal fluid or shunt hardware culture that yielded the pathogenic micro-organism with associated compatible symptoms and signs of central nervous system infection or shunt malfunction; or (2) surgical incision site infection requiring shunt reinsertion (even in the absence of positive culture); or (3) intraperitoneal pseudocyst formation (even in the absence of positive culture). Secondary endpoints were shunt malfunction, defined as unsatisfactory cerebrospinal fluid drainage that required shunt reinsertion, and 30-day mortality.

Results: A primary ventriculoperitoneal shunt was inserted in 538 patients during the study period. The mean age of patients was 48 years (range, 13-88 years) with a male-to-female ratio of 1:1. Aneurysmal subarachnoid haemorrhage was the most common aetiology $(n=169,31 \%)$ followed by intracranial tumour $(\mathrm{n}=164,30 \%)$, central nervous system infection $(\mathrm{n}=42,8 \%)$, and traumatic brain injury $(n=27,5 \%)$. The mean operating time was 75 (standard deviation, 29) minutes. Shunt reinsertion and infection rates were $16 \% \quad(\mathrm{n}=87)$ and $7 \%$ $(n=36)$, respectively. The most common cause for

This article was published on 26 Aug 2016 at www.hkmj.org. shunt reinsertion was malfunction followed by shunt infection. Independent predictors for shunt infection were: traumatic brain injury (adjusted

odds ratio $=6.2 ; 95 \%$ confidence interval, 2.3-16.8), emergency shunting $(2.3 ; 1.0-5.1)$, and prophylactic vancomycin as the sole antibiotic (3.4; 1.1-11.0). The 30 -day all-cause mortality was $6 \%$ and none were directly procedure-related.

Conclusions: This is the first Hong Kong territorywide review of infection in primary ventriculoperitoneal shunts. Although the ventriculoperitoneal shunt infection rate met international standards, there are areas of improvement such as vancomycin administration and the avoidance of scheduling the procedure as an emergency.

\section{Hong Kong Med J 2016;22:410-9}

DOI: 10.12809/hkmj154735

\section{PYM Woo *, MMedSc \\ HT Wong, FRCSEd (SN) \\ ${ }^{2}$ JKS Pu, FRCSEd (SN) \\ ${ }^{3}$ WK Wong, FRCSEd (SN) \\ ${ }^{4}$ LYW Wong, FRCSEd (SN) \\ ${ }^{5}$ MWY Lee, FRCSEd (SN) \\ ${ }^{6} \mathrm{KY}$ Yam, FRCSEd (SN) \\ ${ }^{2}$ WM Lui, FRCSEd (SN) \\ ${ }^{7}$ WS Poon, FRCSEd (SN)}

\section{Department of Neurosurgery, Kwong Wah Hospital, Yaumatei, Hong Kong 2 Division of Neurosurgery, Department of Surgery, Queen Mary Hospital, Pokfulam, Hong Kong \\ ${ }^{3}$ Department of Neurosurgery, Princess Margaret Hospital, Laichikok, Hong Kong \\ ${ }^{4}$ Department of Neurosurgery, Queen Elizabeth Hospital, Jordan, Hong Kong \\ ${ }^{5}$ Department of Neurosurgery, Pamela Youde Nethersole Eastern Hospital, Chai Wan, Hong Kong \\ ${ }^{6}$ Department of Neurosurgery, Tuen Mun Hospital, Tuen Mun, Hong Kong \\ Division of Neurosurgery, Department of Surgery, Prince of Wales Hospital, Shatin, Hong Kong}

* Corresponding author: wym307@ha.org.hk

This paper was presented at the 21st Annual Scientific Meeting of the Hong Kong Neurosurgical Society, 6 December 2014, Hong Kong.

New knowledge added by this study

- The local rate of infection in ventriculoperitoneal (VP) shunts meets international standards.

- Vancomycin antibiotic prophylaxis is a risk factor for shunt infection and is a novel finding.

- VP shunt inserted as an emergency procedure is the strongest risk factor for infection.

Implications for clinical practice or policy

- There is a need to review prophylactic vancomycin administration in terms of timing, dosage, and the need for its combination with another antibiotic.

- Emergency VP shunting is not recommended. Shunts should be implanted whenever possible as an elective procedure.

- A comprehensive local shunt surgery protocol to reduce the risk of shunt infection is recommended. 


\section{Introduction}

Ventriculoperitoneal (VP) shunting is one of the most common neurosurgical procedures performed to treat patients with hydrocephalus, which is a disorder related to an abnormal accumulation of cerebrospinal fluid (CSF) in the brain. The operation involves diverting CSF from the ventricles of the brain to the peritoneal cavity of the abdomen by catheter implantation. Despite being a wellestablished procedure, shunt failure can be as high as $70 \%$ in the first year with an annual occurrence rate of $5 \%$ thereafter. ${ }^{1}$ One of the main causes for failure is shunt infection, a potentially debilitating complication that more than doubles the risk of death and exposes affected patients to 3 times as many neurosurgical procedures as non-infected patients. ${ }^{2}$ Shunt infection varies and occurs in 3\% to $17 \%$ of patients. Standard management involves intravenous antibiotic therapy, shunt removal, insertion of an external ventricular drain, and replacement with a new shunt once the patient's CSF is free of microbial infection. ${ }^{1,3-6}$ The economic impact of VP shunt infection can be considerable. In the US, the median cost per episode per patient has been reported as US $\$ 23500$, accountable for US $\$ 2.0$ billion in annual hospital charges. ${ }^{7,8}$ Evidence suggests that the adoption of a strict institutional implantation protocol can significantly reduce the risk of this most challenging shunt complications. . $^{9-12}$ This retrospective study aimed to determine the frequency of primary VP shunt reinsertions and infection among patients treated in Hong Kong's public health system and to identify risk factors for shunt infection.

\section{Methods}

This was a multicentre retrospective study of patients who underwent VP shunt implantation at all seven Hong Kong Hospital Authority neurosurgical units. The Hospital Authority is a public service highly subsidised by the Hong Kong Special Administrative Region Government, and responsible for delivering health care for $90 \%$ of inpatient bed days in the city. ${ }^{13}$ Clinical research ethics committee approval was obtained from the participating centres. Patients who underwent primary VP shunting from 1 January 2009 to 31 December 2011 were included in this study. Those who underwent alternative CSF diversion procedures or those with a history of VP shunt implantation were excluded from this review. Data from clinical records, operation notes, medicationdispensing records, CSF biochemistry, cell counts, and microbiological cultures were collected. The primary endpoint for this study was primary VP shunt infection. The criteria for shunt infection were: (1) CSF or shunt hardware culture that yielded the pathogenic micro-organism with associated

\section{初次性腦室腹腔分流術的結果 : 分流感染及其危 險因素的多中心臨床審計}

香港神經外科手術成效監察工作組；胡日明、黃海東、 浦勤孫、黃偉基、黃旭榮、李永恩、任廣銳、呂偉文、潘偉生 目的：找出醫院管理局轄下神經外科中心的初次性腦室腹腔分流術後 的感染率, 並確定其潛在的風險因素。

方法: 這個多中心回溯性隊列研究的對象為2009年1月1日至2011年 12 月 31 日期間, 到醫院管理局轄下的神經外科中心接受初次性腦室 腹腔分流術的所有病人。主要評估點為分流術後的感染, 其定義為 :

(1) 腦脊液或分流裝置的病原微生物培養測試呈陽性並出現中樞神 經系統感染或分流故障的相關症狀; 或 (2) 手術切口部位感染而須 重置分流管（即使在沒有陽性培養物的情況下）; 或（3）腹腔假性 囊腫形成（即使在沒有陽性培養物的情況下）。次要評估點為分流故 障, 即是腦脊液引流成效欠佳而須重置引流管, 以及 30 天死亡率。

結果: 研究期間共有 538 名病人接受初次性腦室腹腔分流術。患者平 均年齡48歲 (介乎 $13-88$ 歲), 男女比例為 $1: 1$ 。蛛網膜下腔出血是 最常見的病因（169例，31\%），其次為顱內腫瘤（164例，30\%） 中樞神經系統感染 $(42$ 例, $8 \%$ ) 和創傷性腦損傷 $(27$ 例, $5 \%$ )。手 術時間平均為 75 分鐘（標準差 29 分鐘）。分流管重置率和感染率分別 為16\%（87例）和7\%（36例）。須重置分流管最常見的原因是出現故 障, 其次為分流管感染。分流管感染的獨立預測因素為: 創傷性腦損 傷（調整後比值比 $=6.2 ； 95 \%$ 置信區間2.3-16.8）、緊急分流 (2.3; 1.0-5.1) 和以萬古徽素作為唯一的預防性抗生素 (3.4；1.1-11.0)。 30 日全因死亡率為 $6 \%$, 沒有死亡病例與手術相關。

結論：這是首個有關初次性腦室腹腔分流術的全港性審查研究。儘管 腦室腹腔分流術的感染率達到國際標準, 但仍有可改進的地方, 如萬 古徽素的使用和避免把分流術作為緊急程序。

compatible symptoms and signs of central nervous system (CNS) infection or shunt malfunction ${ }^{5,14,15}$; or (2) surgical incision site infection, as defined by the National Nosocomial Infection Surveillance System, requiring shunt reinsertion (even in the absence of a positive culture $)^{16}$; or (3) intraperitoneal pseudocyst formation (even in the absence of a positive culture). Secondary endpoints were shunt malfunction, defined as unsatisfactory CSF drainage that required shunt reinsertion, and 30-day mortality. Potential risk factors for shunt infection were classified as patient-, disease-, or surgical-related factors. All subjects were followed up for at least 30 days from the operation date or until death.

Statistical analysis was carried out using Pearson's Chi squared test, Fisher's exact test, and binary logistic regression to identify risk factors for shunt infection. The Kaplan-Meier (log-rank) and Cox proportional hazards models were employed for survival analysis. Patient, disease, and surgical factors were used as covariates and a stepwise regression strategy was adopted (Table 1). P values of $<0.05$ were considered statistically significant. All tests were performed using the Statistical Package 
TABLE I. Clinical characteristics of patients with primary ventriculoperitoneal shunt and univariate logistic regression for shunt infection*

\begin{tabular}{|c|c|c|c|c|}
\hline Characteristic & $\begin{array}{l}\text { Overall } \\
(n=538)\end{array}$ & $\begin{array}{c}\text { No shunt } \\
\text { infection } \\
(n=502)\end{array}$ & $\begin{array}{c}\text { With shunt } \\
\text { infection } \\
(n=36)\end{array}$ & $\begin{array}{c}\text { Univariate logistic } \\
\text { regression, OR } \\
(95 \% \mathrm{Cl})\end{array}$ \\
\hline \multicolumn{5}{|l|}{ Patient factor } \\
\hline Sex (male:female) & $1: 1$ & $1: 1$ & $2: 1$ & $2.2(1.1-4.5)$ \\
\hline Age (years) & $48 \pm 13$ & $47 \pm 23$ & $51 \pm 21$ & NS \\
\hline \multicolumn{5}{|l|}{ Age } \\
\hline$\leq 1$ Month & $4(1)$ & $4(1)$ & 0 & NS \\
\hline 1 To $<6$ months & $32(6)$ & $29(6)$ & $3(8)$ & NS \\
\hline 6 Months to $<1$ year & $12(2)$ & $12(2)$ & 0 & NS \\
\hline 1 To $<12$ years & $22(4)$ & $21(4)$ & $1(3)$ & NS \\
\hline 12 To $<18$ years & $10(2)$ & $10(2)$ & 0 & NS \\
\hline$<1$ Year & $48(9)$ & $45(9)$ & $3(8)$ & NS \\
\hline$<18$ Years & $80(15)$ & $76(15)$ & $4(11)$ & NS \\
\hline \multicolumn{5}{|l|}{ Disease factor } \\
\hline Aneurysmal SAH & $169(31)$ & $154(31)$ & $15(42)$ & NS \\
\hline CNS neoplasm & $164(30)$ & $161(32)$ & $3(8)$ & NS \\
\hline Spontaneous intracerebral or intraventricular haemorrhage & $64(12)$ & $58(12)$ & $6(16)$ & NS \\
\hline CNS infection & $42(8)$ & $40(8)$ & $2(6)$ & NS \\
\hline Trauma & 27 (5) & $19(4)$ & $8(22)$ & $7.8(2.9-18.1)$ \\
\hline Normal-pressure hydrocephalus & $18(3)$ & $16(3)$ & $2(6)$ & NS \\
\hline Miscellaneous $\dagger$ & $54(10)$ & - & - & - \\
\hline \multicolumn{5}{|l|}{ Preoperative CSF } \\
\hline RBC count $(/ \mu \mathrm{L})$ & $1900 \pm 3434$ & $1990 \pm 3482$ & $1092 \pm 2913$ & NS \\
\hline WBC count $(/ \mu \mathrm{L})$ & $17 \pm 88$ & $19 \pm 93$ & $4 \pm 1$ & NS \\
\hline Protein (g/L) & $0.78 \pm 1.11$ & $0.80 \pm 1.15$ & $0.53 \pm 0.64$ & NS \\
\hline Glucose (mmol/L) & $3.6 \pm 1.2$ & $3.6 \pm 1.2$ & $3.4 \pm 1.1$ & NS \\
\hline \multicolumn{5}{|l|}{ Surgical factor } \\
\hline Mean No. of previous cranial operations & 2 & 2 & 3 & NS \\
\hline \multicolumn{5}{|l|}{ Antiseptic for skin preparation } \\
\hline Povidone-iodine $10 \%$ & $538(100)$ & $502(100)$ & $36(100)$ & NS \\
\hline Ethanol $70 \%$ & $52(10)$ & $51(10)$ & $1(3)$ & NS \\
\hline Alcoholic chlorhexidine gluconate $2 \%$ & $233(43)$ & $216(43)$ & $17(47)$ & NS \\
\hline Aqueous chlorhexidine gluconate $4 \%$ & $233(43)$ & $216(43)$ & $17(47)$ & NS \\
\hline Single agent antiseptic & $116(22)$ & $112(22)$ & $4(11)$ & NS \\
\hline Operating time (mins) & $75 \pm 29$ & $75 \pm 29$ & $69 \pm 32$ & NS \\
\hline \multicolumn{5}{|l|}{ Antibiotic prophylaxis } \\
\hline Cefazolin & $64(12)$ & $62(12)$ & $2(6)$ & NS \\
\hline $\begin{array}{l}\text { Third-generation cephalosporin (ceftriaxone / cefotaxime / cefoperazone / } \\
\text { ceftazidime) }\end{array}$ & $328(61)$ & $304(61)$ & $24(67)$ & NS \\
\hline Vancomycin & $40(7)$ & $34(7)$ & $6(17)$ & $3.7(1.3-10.5)$ \\
\hline Duration of antibiotic prophylaxis (days) & $2 \pm 4$ & $2 \pm 4$ & $4 \pm 7$ & NS \\
\hline Additional procedure & $24(4)$ & $24(5)$ & 0 & NS \\
\hline Emergency shunting & $312(58)$ & $286(57)$ & $26(72)$ & $2.2(1.0-4.7)$ \\
\hline Burr hole location & & & & NS \\
\hline Frontal & $135(25)$ & $128(25)$ & 7 (19) & \\
\hline Parietal & $320(59)$ & $295(59)$ & $25(69)$ & \\
\hline Occipital & $81(15)$ & $77(15)$ & $4(11)$ & \\
\hline Old burr hole & $28(5)$ & $27(5)$ & $1(3)$ & NS \\
\hline Median No. of surgeons & 2 & 2 & 2 & NS \\
\hline Higher neurosurgical traineeł & $174(32)$ & $160(32)$ & $14(39)$ & NS \\
\hline Valve design§ & & & & NS \\
\hline Integra Pudenz (Integra LifeSciences Corporation, Plainsboro [NJ], US) & $324(60)$ & $302(60)$ & $22(61)$ & \\
\hline Medtronic Strata II (Medtronic, Minneapolis [MN], US) & $84(16)$ & $75(15)$ & $9(25)$ & \\
\hline Medtronic Delta (Medtronic, Minneapolis [MN], US) & $67(12)$ & $64(13)$ & $3(8)$ & \\
\hline $\begin{array}{l}\text { Codman Hakim (Codman and Shurtleff Inc, Johnson and Johnson, Raynham } \\
\text { [MA], US) }\end{array}$ & $52(10)$ & $51(10)$ & $1(3)$ & \\
\hline Aesculap proGAV (Aesculap-Miethke, Potsdam, Germany) & $6(1)$ & $5(1)$ & $1(3)$ & \\
\hline Valve pressure§ & & & & NS \\
\hline Fixed & $390(72)$ & $364(73)$ & $26(72)$ & \\
\hline Programmable & $147(27)$ & $137(27)$ & $10(28)$ & \\
\hline
\end{tabular}

Abbreviations: $\mathrm{Cl}=$ confidence interval; CNS = central nervous system; CSF = cerebrospinal fluid; NS = not significant; OR = odds ratio; RBC = red blood cell; $\mathrm{SAH}=$ subarachnoid haemorrhage; $\mathrm{WBC}=$ white blood cell

* Data are shown in No., No. (\%) or mean \pm standard deviation, unless otherwise specified

+ Miscellaneous conditions: haemorrhagic stroke due to arteriovenous malformation $(n=16)$, communicating hydrocephalus (not otherwise specified) $[n=9]$, aqueductal stenosis $(n=7)$, spinal dysraphism $(n=5)$, Dandy-Walker malformation $(n=4)$, cerebral infarction $(n=4)$, mass effect from aneurysm or arteriovenous malformation ( $n=2)$, benign intracranial hypertension $(n=2)$, craniocervical compression $(n=2)$, dural venous sinus thrombosis $(n=1)$, subdural effusion $(n=1)$, and craniosynostosis $(n=1)$

‡ Most senior surgeon listed in operation record

$\S$ Data of valve design in 5 patients and valve pressure in I patient are missing 
for the Social Sciences (Windows version 16.0.1; SPSS Inc, Chicago [IL], US).

\section{Results}

During the 3-year period, 538 patients underwent primary VP shunt implantation and $87 \%(n=470)$ had complete clinical follow-up with a median duration of 37 months (range, 3 days to 76 months). Seven (1\%) patients were transferred to other hospitals within 30 days of the procedure. The median duration of hospitalisation was 42 days (range, 3 days to 36 months) and the median length of time from admission to shunting was 18 days (range, $<1$ day to 21 months). The clinical features and surgical variables are presented in Table 1 . The mean $( \pm$ standard deviation) age of patients was $48 \pm 13$ years (range, 13-88 years) and the male-to-female ratio was $1: 1$. In the study group, $80(15 \%)$ were paediatric patients and 48 (9\%) were infants. Overall, primary VP shunting was performed for post-aneurysmal subarachnoid haemorrhage communicating hydrocephalus in 169 (31\%) patients, for CNS neoplasms in 164 (30\%) patients, and for spontaneous intracerebral or intraventricular haemorrhage in 64 (12\%) patients. For patients who had preoperative CSF sampling performed, the mean red blood cell count was $1900 / \mu \mathrm{L}$, white cell count was $17 / \mu \mathrm{L}$, total protein level was $0.78 \mathrm{~g} / \mathrm{L}$, and glucose level was $3.6 \mathrm{mmol} / \mathrm{L}$.

Over one quarter of patients $(n=155,29 \%)$ had never had prior cranial neurosurgery and approaching half had undergone either one $(n=141,26 \%)$ or two $(\mathrm{n}=115,21 \%)$ previous procedures. Antiseptic skin preparation was povidone-iodine $10 \%$ combined with another antiseptic in 422 (78\%) patients and with povidone iodine alone in the remainder. The mean operating time for VP shunting was $75 \pm 29$ minutes. All patients had antibiotic prophylaxis of whom 328 (61\%) were prescribed a third-generation cephalosporin and 40 (7\%) had vancomycin. Twelve (2\%) patients had a rifampicin-clindamycin antibiotic-impregnated ventricular catheter as part of the shunt system. The majority of operations were performed in an emergency setting $(n=312$, $58 \%$ ) and shunt implantation was the sole procedure performed $(n=514,96 \%)$. The burr hole was most frequently positioned at the parietal location in 320 (59\%) patients and 135 (25\%) had a frontal burr hole. New burr holes were fashioned for shunt placement $95 \%$ of the time. The median number of surgeons was two, with a third of shunts performed by higher neurosurgical trainees $(n=174,32 \%)$ and the remaining performed by a neurosurgical specialist. Almost three quarters of VP shunts had a fixedpressure valve $(n=390,72 \%)$ and the predominant design utilised was the Integra Pudenz flushing valve (Integra LifeSciences Corporation, Plainsboro [NJ], US) in $324(60 \%)$ patients.
The rate of VP shunt reinsertion was $16 \%$ $(\mathrm{n}=87)$ and infection was $7 \%(\mathrm{n}=36)$. The main causes for reinsertion were malfunction (9\%) followed by infection. The annual proportion of shunts that required reoperation or were infected was comparable $(\mathrm{P}=0.87)$ [Fig 1]. The median time from shunt implantation to shunt removal for infection was 64 days (range, 2 days to 10 months). A cumulative risk for infection was noted affecting $3 \%$ of shunts in the first 30 days, $6 \%$ in 6 months, and $7 \%$ in 1 year. Although 68 (13\%) patients were lost to follow-up, attrition analysis revealed that this did not affect infection rates. The mean followup duration in this subgroup between those with infection and those without was comparable at 526 days and 554 days, respectively $(\mathrm{P}=0.43)$. In addition, the incidence of shunt infection in patients with incomplete follow-up (5\%) was similar to those with complete follow-up (7\%) $[\mathrm{P}=0.42]$.

Most infections manifested as meningitis or ventriculitis $(n=19,53 \%)$, followed by wound breakdown $(n=15,42 \%)$ and peritonitis $(n=2$, $6 \%$ ). The most common causative bacteria were coagulase-negative staphylococci (CoNS) [n=25, $69 \%$ ] of which methicillin resistance was detected in $19(76 \%)$ patients (Table 2). All CoNS species were sensitive to vancomycin with a quarter of methicillin-resistant (MR) species susceptible to aminoglycosides such as gentamicin or amikacin. The second most common infective agent affecting four (11\%) patients was MR Staphylococcus aureus (MRSA). Polymicrobial infection was evident in six $(17 \%)$ patients. One patient with peritonitis had mixed Gram-positive and -negative microorganisms from CSF cultures.

The only patient risk factor for shunt infection was sex (Table 1). Male patients had a greater than

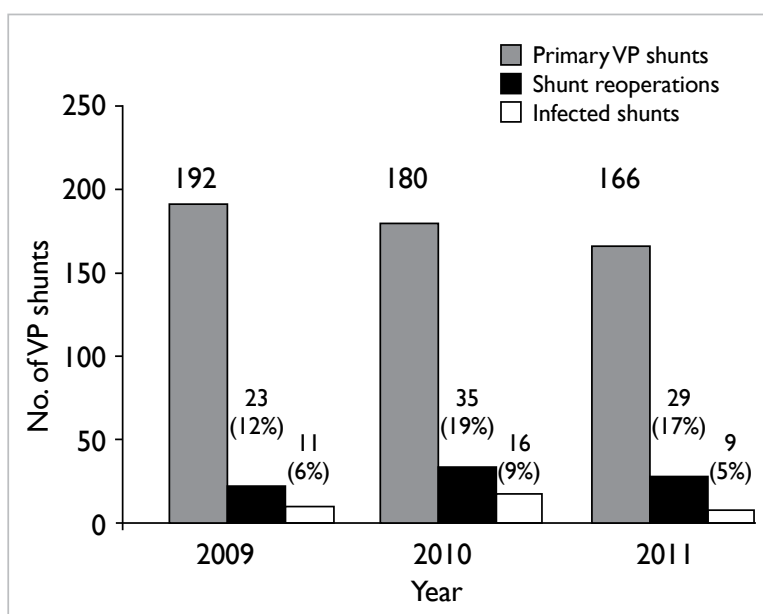

FIG I. Comparison of the total number of primary ventriculoperitoneal (VP) shunts performed from 2009 to 2011 with the number of shunt reoperations and infected shunts 
two-fold increased odds of infection (odds ratio $[\mathrm{OR}]=2.2$; 95\% confidence interval $[\mathrm{CI}], 1.1-4.5)$. Traumatic brain injury (TBI) was the only disease risk factor $(\mathrm{OR}=7.8 ; 95 \% \mathrm{CI}, 2.9-18.1)$. Surgical factors included the use of vancomycin as the prophylactic antibiotic $(\mathrm{OR}=3.7 ; 95 \% \mathrm{CI}, 1.3-10.5)$ and shunts implanted as an emergency procedure $(\mathrm{OR}=2.2 ; 95 \% \mathrm{CI}, 1.0-4.7)$. After adjusting for confounding factors, the independent risk factors for primary VP shunt infection were TBI (adjusted $\mathrm{OR}=6.2$; 95\% CI, 2.3-16.8), the use of vancomycin (adjusted $\mathrm{OR}=3.4 ; 95 \% \mathrm{CI}, 1.1-11.0$ ), and emergency shunting (adjusted OR=2.3; 95\% CI, 1.0-5.1) [Table 3].

With respect to shunt infection, there was a difference in duration of shunt implantation for patients with the aforementioned risk factors as demonstrated by the significant separation of KaplanMeier survival curves (Fig 2). This was ascertained by Cox regression analysis (Table 3 ). Median shunt survival for trauma patients was 35 days (vs 154 days in non-trauma patients), 32 days for patients who received vancomycin (vs 124 days for alternative antibiotics), and 65 days for emergency operations (vs 208 days for elective operations).
In this study, 30-day all-cause mortality was $6 \%(n=32)$, but none was directly procedurerelated. Almost half of these patients $(n=15,47 \%)$ had an underlying malignant CNS tumour; the majority being brain metastases $(n=12,80 \%)$. After accounting for patient age, sex, disease aetiology, shunt reinsertion and infection, a diagnosis of malignant brain tumour was the only significant independent predictor for 30-day mortality with an adjusted OR of 5.6 (95\% CI, 2.6-11.7).

\section{Discussion}

Ventriculoperitoneal CSF shunting has considerably reduced the morbidity and mortality of patients with hydrocephalus since its first description in $1908 .{ }^{17}$ More than a century later the operation remains the mainstay treatment for this condition. Despite the introduction of antibiotics, improvements in shunt materials and surgical techniques, VP shunt complications are common. Long-term epidemiological studies have indicated that more than half of all patients with CSF shunts will require a surgical revision in their lifetime. ${ }^{4,18}$ Shunt infection is a serious complication with potentially

TABLE 2. Micro-organisms cultured from cerebrospinal fluid or shunt hardware from the 36 infected cases with antibiotic sensitivity distribution

\begin{tabular}{|c|c|c|c|c|c|c|c|}
\hline \multirow[t]{2}{*}{ Micro-organism } & \multirow{2}{*}{$\begin{array}{c}\text { Shunt } \\
\text { infection } \\
\text { cases }(n=36)\end{array}$} & \multirow{2}{*}{$\begin{array}{c}\text { Positive } \\
\text { bacterial } \\
\text { cultures }(n=49)\end{array}$} & \multicolumn{5}{|c|}{ Antibiotic sensitivity (\%) } \\
\hline & & & Penicillin group & Cephalosporin & Vancomycin & Aminoglycoside & Clindamycin \\
\hline \multicolumn{8}{|l|}{ Gram-positive } \\
\hline MS CoNS & $6(17)$ & $6(12)$ & $6(100)$ & $6(100)$ & $6(100)$ & $4(67)$ & $5(83)$ \\
\hline MR CoNS & $19(53)$ & $28(57)$ & - & - & $28(100)$ & $7(25)$ & $3(11)$ \\
\hline $\mathrm{MS} \mathrm{SA}^{*}$ & & $1(2)$ & $1(100)$ & $1(100)$ & $1(100)$ & $1(100)$ & $1(100)$ \\
\hline MR SA & $4(11)$ & $5(10)$ & - & - & $5(100)$ & - & $1(20)$ \\
\hline Streptococcus species ${ }^{*}$ & & $4(8)$ & $4(100)$ & $4(100)$ & $4(100)$ & NA & NA \\
\hline \multicolumn{8}{|l|}{ Gram-negative } \\
\hline Escherichia coli* & & $2(4)$ & $2(100)$ & $2(100)$ & - & $2(100)$ & NA \\
\hline Klebsiella pneumoniae* & $1(3)$ & $2(4)$ & $2(100)$ & $2(100)$ & - & $2(100)$ & NA \\
\hline Proteus mirabilis* & & $1(2)$ & $1(100)$ & $1(100)$ & - & $1(100)$ & NA \\
\hline Polymicrobial & $6(17)$ & - & - & - & - & - & - \\
\hline
\end{tabular}

Abbreviations: CoNS = coagulase-negative staphylococci; $M$ R = methicillin-resistant; $M S$ = methicillin-sensitive; $N A=$ data not available; SA = Staphylococcus aureus

* Part of polymicrobial culture

TABLE 3. Independent predictors for primary ventriculoperitoneal shunt infection

\begin{tabular}{lccc}
\hline Predictor & $\begin{array}{c}\text { Multivariate logistic regression, } \\
\text { adjusted OR (95\% Cl) }\end{array}$ & $\begin{array}{c}\text { Median shunt survival (days) } \\
\text { Cox proportional hazards, } \\
\text { adjusted OR (95\% CI) }\end{array}$ & 35 \\
\hline Trauma & $6.2(2.3-16.8)$ & 32 & $3.3(1.3-8.4)$ \\
Vancomycin & $3.4(1.1-11.0)$ & 65 & $1.5(1.3-9.7)$ \\
Emergency operation & $2.3(1.0-5.1)$ & $1.4(1.1-6.7)$ \\
\hline
\end{tabular}

Abbreviations: $\mathrm{Cl}=$ confidence interval; $\mathrm{OR}=$ odds ratio 

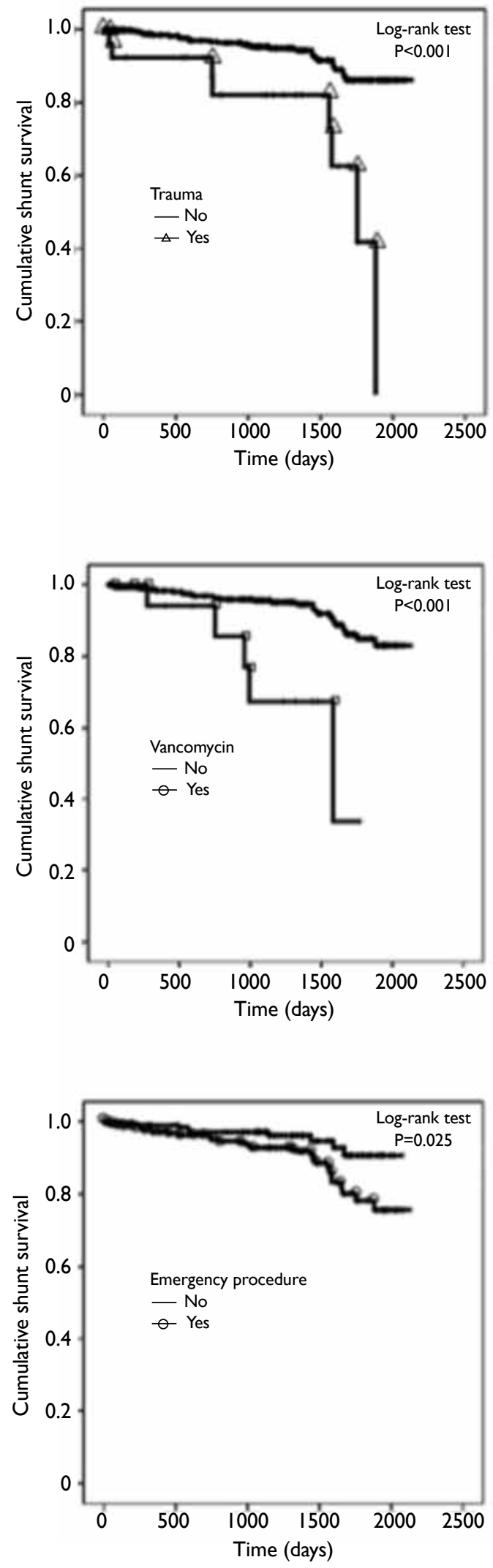

FIG 2. Kaplan-Meier shunt survival analysis

Patients with traumatic brain injury, administered vancomycin as the sole prophylactic antibiotic, or had implantation as an emergency procedure were more likely to experience shunt infection $(P<0.05$, log-rank test) devastating consequences. Observational studies have recorded infection rates ranging between $3 \%$ and $17 \%$, but more consistent estimates from larger patient cohorts cite rates of $6 \%$ to $8 \% .^{1,3-5}$ Our local shunt infection rate of $7 \%$ is relatively lower than other previously published findings and is in keeping with the results from other developed countries.

The wide range of shunt infection rates quoted in the literature is due in part to the diverse definitions adopted for shunt infection and the patient populations studied. Many studies have defined infection as a positive CSF microbial culture or the presence of CSF pleocytosis or low CSF glucose levels with clinical features of CNS infection. ${ }^{3,11,19}$ Due to the study design, a more pragmatic definition was adopted whereby infection was determined retrospectively by either a positive CSF or shunt hardware microbial culture in the presence of shunt malfunction. ${ }^{5,14,15}$ Nonetheless, it is acknowledged that the true incidence of shunt infection may be overestimated by false-positive cultures from skin flora. The reasons for selecting this interpretation for shunt infection were three-fold. First, it allowed for micro-organism identification and consequent epidemiological analysis; second, infection may not be clinically apparent with malfunctioning shunts; and third, CSF cultures alone cannot exclude infection in cases of shunt malfunction. ${ }^{15}$

The only disease risk factor independently associated with VP shunt infection was TBI. This may be due to two reasons. Delayed posttraumatic hydrocephalus invariably occurs in severe TBI patients and develops in over a third of those subject to decompressive craniectomies. ${ }^{20}$ Such patients often have a prolonged hospital stay and undergo multiple operations before a shunt is eventually implanted. In this cohort, TBI patients had a mean duration of hospitalisation of 89 days, which was 2 weeks more than the mean stay of 74 days for hydrocephalic patients with alternative neurosurgical conditions. Protracted hospitalisation may lead to skin colonisation with drug-resistant organisms that can evade single-agent conventional antibiotic prophylaxis. ${ }^{21}$ This is supported by evidence from this study where causative bacteria of shunt infection were resistant to the prescribed prophylactic antibiotic in $80 \%$ of TBI patients. These patients also had a mean number of three prior cranial procedures before shunting compared with two operations in patients with non-traumatic hydrocephalus aetiology. Previous surgery is well known to be a main cause of CSF leak in shunted patients and contributes to an increased risk of infection. ${ }^{5,22}$ Although in this patient series, the number of prior cranial procedures per se did not impart greater risk, detailed clinical data regarding CSF leak in TBI patients were not collected and therefore the influence of TBI on infection can only 
be inferred.

An unexpected finding was that patient age was not a risk factor for shunt infection. This is in contrast to several larger studies that identified paediatric patients, especially infants (younger than a year), to be particularly at risk. ${ }^{11,23}$ Infants have less-developed humoral and cellular immune systems with immature skin growth rendering them more vulnerable to shunt infection. A likely reason for this observation is the small number of paediatric patients $(\mathrm{n}=80,15 \%)$ in this cohort with only $9 \%(n=48)$ being infants. Larger sample size may delineate more distinctive differences among agegroups.

There is little doubt that systemic antibiotic prophylaxis can prevent shunt infection. ${ }^{24} \mathrm{We}$, however, interestingly identified the sole use of vancomycin as a risk factor for shunt infection, a novel observation that has not been previously reported in the literature. The antibiotic was regularly reserved for patients allergic to penicillin-group antibiotics or for those with documented penicillin-resistant microbial infection or colonisation. This finding apparently seems counter-intuitive especially when all causative CoNS identified in this cohort were sensitive to vancomycin. The issue may lie with the timing of its administration before the procedure and its dosage. With regard to timing, systemic vancomycin requires slow intravenous infusion to reduce the risk of a hypersensitivity reaction that manifests as either red man syndrome or anaphylaxis and occurs in $3.7 \%$ to $47 \%$ of patients. ${ }^{25}$ To further illustrate the incidence of these symptoms, the first randomised controlled trial investigating its efficacy in shunt procedures was prematurely discontinued due to these adverse effects. ${ }^{26}$ Most hospital protocols require infusion rates over an hour as a minimum, but clinical trials have demonstrated that even lengthier 2-hour infusions can further reduce the frequency and severity of these reactions. ${ }^{25,27}$ Furthermore, the efficacy of vancomycin to treat CoNS and MRSA infections has been questioned due to observations of slower bactericidal activity, compared with nafcillin, than was previously recognised. ${ }^{28}$ To address this issue we suggest that rigid guidelines should be adhered to with respect to the adequate timing of vancomycin infusion before skin incision. Should more rapid infusions be required, for example, in the emergency setting, pre-administration of intravenous diphenhydramine before vancomycin infusion can prevent the development of red man syndrome..$^{25}$

Limited data are available about the pharmacokinetics and CSF concentrations of vancomycin in neurosurgical patients. In a study reviewing intra-operative serum and CSF vancomycin concentrations of paediatric patients undergoing shunt implantation, the authors noted that CSF penetration was negligible in patients with non-inflamed meninges despite presumed adequate loading doses. ${ }^{29}$ This was echoed in a later study determining that among non-meningitic patients, vancomycin CNS penetration was poor with a CSFto-serum ratio of only $18 \%{ }^{30}$ Its increasing use over the course of decades has also led to a corresponding rise in minimum bactericidal concentrations of CoNS. ${ }^{28}$ These unique findings should prompt an extensive review of prophylactic vancomycin use as there is currently no consensus on a recommended loading dose for neurosurgical procedures. In the meantime, researchers have attempted to improve the bactericidal activity in patients treated with vancomycin with varying measures of success. Vancomycin in combination with gentamicin results in more rapid bactericidal rates in animal models $^{28}$ and has been proven to be as effective as third-generation cephalosporins in preventing surgical site infection for neurosurgical procedures in a randomised trial. ${ }^{31}$ Others have proposed intraoperative combined vancomycin-aminoglycoside administration either intraventricularly, for shunt hardware antibiotic bath immersion prior to implantation or applied in powder form within the subgaleal space of the wound with tenable positive results. ${ }^{11,32-34}$

Antibiotic-impregnated (by rifampicin with either clindamycin or minocycline) and silver-coated ventricular catheters offer the greatest promise in preventing shunt infection. ${ }^{35,36}$ There exists a growing body of evidence in support of antibioticimpregnated ventricular catheters and they are gradually replacing conventional plain silicone catheters in daily practice with considerable cost savings. ${ }^{37-40}$ There are also accompanying concerns about the development of antibiotic-resistant microorganisms and a recent meta-analysis has elucidated the higher risk of Gram-negative and MRSA shunt infections. ${ }^{38}$ In this series, only 12 patients received antibiotic-impregnated catheters during the study period so it is difficult to draw any conclusion about their effectiveness.

Emergency VP shunting is another surgicalrelated risk factor for infection and was performed in more than half of patients who underwent the procedure. Its significance is the greatest among the three independent factors identified and is possibly the most amenable to change in current practice. The clinical condition of most patients with hydrocephalus who require primary VP shunting does not warrant emergency surgery although a few indications exist, for example, obstructive pineal region or cerebellar tumours that may present with acute symptoms. More than two thirds of patients (70\%) in this study had conditions that necessitated delayed shunting when the primary disease had been treated and the patients stabilised. It is most likely 
because of limited availability of operating theatre among other related resources and the general practice that VP shunting is delegated to more junior members of the surgical team that this phenomenon prevails. Several reasons support why 'emergency' primary shunting should be discouraged. It has long been established by several protocol-driven trials that shunting should be performed as the first procedure of the operative day to minimise the risk of contamination. ${ }^{9-11}$ To illustrate, a surgical incision time after 10 am was observed to be a predictor for infection..$^{5}$ In elective procedures the neurosurgeon in-charge and other responsible operating theatre staff are likely to be more experienced in comparison with personnel involved in emergencies. In particular, it has been shown that individual surgical experience is an important factor for infection with researchers stating a higher incidence among neurosurgical trainees or in surgeons who performed fewer than 147 shunts within a decade. ${ }^{4,41}$ Nonetheless, using the former stratification of trainee versus specialist, this was not evident in our cohort. Another argument against 'emergency' VP shunting could be the location where the procedure is performed. For a variety of resource allocation reasons, shunting scheduled as an emergency procedure is often not performed in neurosurgery-designated operating theatres. A study investigating the distribution of bacteria in the operating room environment and its relationship with ventricular shunt infections concluded that positive environmental cultures were more likely to occur in a theatre not devoted to neurosurgery ${ }^{42}$ Although procedure timing and location were not explored in this audit, it is believed that they were the principal explanations why shunts implanted as an emergency were more likely to become infected.

The time interval from shunt implantation to revision for infection in our study is longer than most published data with a median shunt survival of 64 days. ${ }^{5,34}$ Our data show that $92 \%(n=33)$ of shunt infections occurred within 6 months and is compatible with the commonly held belief that the infection begins intra-operatively with the inoculation of skin flora, either from the patient or surgeon, into the surgical wound. ${ }^{42-44}$ This is further substantiated by the predominance of CoNS and $S$ aureus in $81 \%$ of bacterial cultures in this patient series and similarly in several previous reports. . $5,9-12,32,35,36,43$ Coupled with positive research findings that theatre discipline during surgery reduces infection risk, it seems reasonable to conclude that institutional shunt implantation protocols should be established..$^{9-12,32}$

Even though the performance of our neurosurgical community with regard to primary VP shunt infection meets international standards, there is room for improvement. The implementation of a standardised shunt surgery protocol that covers preoperative preparation as well as intra-operative and postoperative management has consistently been proven to be effective in reducing infection..$^{9-12,32}$ The landmark study by Choux at $\mathrm{al}^{10}$ first demonstrated that meticulous measures-such as adopting a notouch technique for shunt handling, limiting the length of shunt exposure time and the number of people in the operating room-have dramatically decreased shunt infection rates from $16 \%$ to less than $1 \%$. It is our belief that a similarly comprehensive protocol should be developed and based on the findings of this preliminary study.

This study has several limitations. Data collection was retrospective so key clinical information such as the presence of CSF leak and patient co-morbidities were missing. This may have led to inadequate control for confounding factors. An additional limitation inherent in studies of this nature is the potential presence of observational bias where data were collected without blinding after outcomes were known. Follow-up was incomplete with 68 (13\%) patients defaulting from clinical review over the course of 3 years. Inadequate followup duration was also noted; seven (1\%) patients were transferred to other hospitals within 30 days of the procedure and this might have influenced 30-day all-cause mortality findings. Finally, our definition of shunt infection did not include abnormal CSF biochemistry criteria that could have confirmed or refuted positive culture results of specimens that might have been contaminated during collection.

\section{Conclusions}

This is the first territory-wide review of infection in primary VP shunts conducted in Hong Kong's public health care setting. This study is also one of the largest in the literature examining shunt infection complications among a predominantly Chinese population. Shunt infection was the second most common cause for reinsertion occurring in $7 \%$ of patients. Significant independent predictors for shunt infection were TBI, vancomycin administration for prophylaxis, and procedures performed in an emergency setting. Although VP shunt infection rates meet international standards, there are areas of improvement that can be readily addressed such as the timing or dosage of vancomycin and the avoidance of performing the procedure as an emergency. The best approach to reducing shunt infection may be the design and adoption of a standardised shunt surgery protocol customised to local practice.

\section{Acknowledgements}

We would like to thank members of the Hospital Authority Head Office (HAHO) Coordinating Committee (Neurosurgery), the Clinical Effectiveness \& Technology Management 
Department, the Division of Quality and Safety, and the Clinical Data Analysis and Reporting System Team, HAHO IT Service for their administrative advice and data collection. We also wish to thank Drs Chris YW Liu, Alphon HY Ip, and Claudia Law for their contributions in data collection and entry. This study was supported by the Tung Wah Group of Hospitals Neuroscience Research Fund.

\section{Declaration}

All authors have disclosed no conflicts of interest.

\section{References}

1. Wong JM, Ziewacz JE, Ho AL, et al. Patterns in neurosurgical adverse events: cerebrospinal fluid shunt surgery. Neurosurg Focus 2012;33:E13.

2. Schoenbaum SC, Gardner P, Shillito J. Infections of cerebrospinal fluid shunts: epidemiology, clinical manifestations, and therapy. J Infect Dis 1975;131:543-52.

3. Birjandi A, Zare E, Hushmandi F. Ventriculoperitoneal shunt infection: a review of treatment. Neurosurg Q 2012;22:145-8.

4. Borgbjerg BM, Gjerris F, Albeck MJ, Børgesen SE. Risk of infection after cerebrospinal fluid shunt: an analysis of 884 first-time shunts. Acta Neurochir (Wien) 1995;136:1-7.

5. Korinek AM, Fulla-Oller L, Boch AL, Golmard JL, Hadiji B, Puybasset L. Morbidity of ventricular cerebrospinal fluid shunt surgery in adults: an 8-year study. Neurosurgery 2011;68:985-94; discussion 994-5.

6. Patwardhan RV, Nanda A. Implanted ventricular shunts in the United States: the billion-dollar-a-year cost of hydrocephalus treatment. Neurosurgery 2005;56:139-44; discussion 144-5.

7. Simon TD, Riva-Cambrin J, Srivastava R, et al. Hospital care for children with hydrocephalus in the United States: utilization, charges, comorbidities, and deaths. J Neurosurg Pediatr 2008;1:131-7.

8. Shannon CN, Simon TD, Reed GT, et al. The economic impact of ventriculoperitoneal shunt failure. J Neurosurg Pediatr 2011;8:593-9.

9. Faillace WJ. A no-touch technique protocol to diminish cerebrospinal fluid shunt infection. Surg Neurol 1995;43:344-50.

10. Choux M, Genitori L, Lang D, Lena G. Shunt implantation: reducing the incidence of shunt infection. J Neurosurg 1992;77:875-80.

11. Kestle JR, Riva-Cambrin J, Wellons JC 3rd, et al. A standardized protocol to reduce cerebrospinal fluid shunt infection: the Hydrocephalus Clinical Research Network Quality Improvement Initiative. J Neurosurg Pediatr 2011;8:22-9.

12. Pirotte BJ, Lubansu A, Bruneau M, Loqa C, Van Cutsem $\mathrm{N}$, Brotchi J. Sterile surgical technique for shunt placement reduces the shunt infection rate in children: preliminary analysis of a prospective protocol in 115 consecutive procedures. Childs Nerv Syst 2007;23:1251-61.

13. World Health Organization and Department of Health, Hong Kong. Hong Kong (China) health service delivery profile, 2012. Available from: http://www.wpro.who.int/ health_services/service_delivery_profile_hong_kong_ (china).pdf. Accessed Mar 2016.
14. Overturf GD. Defining bacterial meningitis and other infections of the central nervous system. Pediatr Crit Care Med 2005;6 Suppl:S14-8.

15. Vanaclocha V, Sáiz-Sapena N, Leiva J. Shunt malfunction in relation to shunt infection. Acta Neurochir (Wien) 1996;138:829-34.

16. Horan TC, Gaynes RP, Martone WJ, Jarvis WR, Emori TG. CDC definitions of nosocomial surgical site infections, 1992: a modification of CDC definitions of surgical wound infections. Infect Control Hosp Epidemiol 1992;13:6068.

17. Kausch W. Die behandlung des hydrocephalus der kleinen kinder. Arch Klin Chir 1908;87:709-96.

18. Tuli S, Drake J, Lawless J, Wigg M, Lamberti-Pasculli M. Risk factors for repeated cerebrospinal shunt failures in pediatric patients with hydrocephalus. J Neurosurg 2000;92:31-8.

19. Odio C, McCracken GH Jr, Nelson JD. CSF shunt infections in pediatrics. A seven-year experience. Am J Dis Child 1984;138:1103-8.

20. Honeybul S, Ho KM. Incidence and risk factors for post-traumatic hydrocephalus following decompressive craniectomy for intractable intracranial hypertension and evacuation of mass lesions. J Neurotrauma 2012;29:1872-8.

21. Wang KW, Chang WN, Shih TY, et al. Infection of cerebrospinal fluid shunts: causative pathogens, clinical features, and outcomes. Jpn J Infect Dis 2004;57:44-8.

22. Jeelani NU, Kulkarni AV, Desilva P, Thompson DN, Hayward RD. Postoperative cerebrospinal fluid wound leakage as a predictor of shunt infection: a prospective analysis of 205 cases. Clinical article. J Neurosurg Pediatr 2009;4:166-9.

23. Davis SE, Levy ML, McComb JG, Masri-Lavine L. Does age or other factors influence the incidence of ventriculoperitoneal shunt infections? Pediatr Neurosurg 1999;30:253-7.

24. Ratilal B, Costa J, Sampaio C. Antibiotic prophylaxis for surgical introduction of intracranial ventricular shunts. Cochrane Database Syst Rev 2006;(3):CD005365.

25. Sivagnanam S, Deleu D. Red man syndrome. Crit Care 2003;7:119-20.

26. Odio C, Mohs E, Sklar FH, Nelson JD, McCracken GH Jr. Adverse reactions to vancomycin used as prophylaxis for CSF shunt procedures. Am J Dis Child 1984;138:17-9.

27. Healy DP, Sahai JV, Fuller SH, Polk RE. Vancomycininduced histamine release and "red man syndrome": comparison of 1- and 2-hour infusions. Antimicrob Agents Chemother 1990;34:550-4.

28. Stevens DL. The role of vancomycin in the treatment paradigm. Clin Infect Dis 2006;42 Suppl 1:S51-7.

29. Fan-Havard P, Nahata MC, Bartkowski MH, Barson WJ, Kosnik EJ. Pharmacokinetics and cerebrospinal fluid (CSF) concentrations of vancomycin in pediatric patients undergoing CSF shunt placement. Chemotherapy 1990;36:103-8.

30. Albanèse J, Léone $M$, Bruguerolle $B$, Ayem $M L$, Lacarelle B, Martin C. Cerebrospinal fluid penetration and pharmacokinetics of vancomycin administered by continuous infusion to mechanically ventilated patients in an intensive care unit. Antimicrob Agents Chemother 2000;44:1356-8.

31. Pons VG, Denlinger SL, Guglielmo BJ, et al. Ceftizoxime versus vancomycin and gentamicin in neurosurgical 
prophylaxis: a randomized, prospective, blinded clinical study. Neurosurgery 1993;33:416-22; discussion 422-3.

32. Choksey MS, Malik IA. Zero tolerance to shunt infections: can it be achieved? J Neurol Neurosurg Psychiatry 2004;75:87-91.

33. Abdullah KG, Attiah MA, Olsen AS, Richardson A, Lucas $\mathrm{TH}$. Reducing surgical site infections following craniotomy: examination of the use of topical vancomycin. J Neurosurg 2015;123:1600-4.

34. Ragel BT, Browd SR, Schmidt RH. Surgical shunt infection: significant reduction when using intraventricular and systemic antibiotic agents. J Neurosurg 2006;105:242-7.

35. Keong NC, Bulters DO, Richards HK, et al. The SILVER (Silver Impregnated Line Versus EVD Randomized trial): a double-blind, prospective, randomized, controlled trial of an intervention to reduce the rate of external ventricular drain infection. Neurosurgery 2012;71:394-403; discussion 403-4.

36. Sciubba DM, Stuart RM, McGirt MJ, et al. Effect of antibiotic-impregnated shunt catheters in decreasing the incidence of shunt infection in the treatment of hydrocephalus. J Neurosurg 2005;103 Suppl:131-6.

37. Thomas R, Lee S, Patole S, Rao S. Antibiotic-impregnated catheters for the prevention of CSF shunt infections: a systematic review and meta-analysis. Br J Neurosurg 2012;26:175-84.

38. Konstantelias AA, Vardakas KZ, Polyzos KA, Tansarli GS,
Falagas ME. Antimicrobial-impregnated and -coated shunt catheters for prevention of infections in patients with hydrocephalus: a systematic review and meta-analysis. J Neurosurg 2015;122:1096-112.

39. Parker SL, Farber SH, Adogwa O, Rigamonti D, McGirt MJ. Comparison of hospital cost and resource use associated with antibiotic-impregnated versus standard shunt catheters. Clin Neurosurg 2011;58:122-5.

40. Parker SL, McGirt MJ, Murphy JA, Megerian JT, Stout M, Engelhart L. Cost savings associated with antibioticimpregnated shunt catheters in the treatment of adult and pediatric hydrocephalus. World Neurosurg 2015;83:382-6.

41. Cochrane DD, Kestle JR. The influence of surgical operative experience on the duration of first ventriculoperitoneal shunt function and infection. Pediatr Neurosurg 2003;38:295-301.

42. Duhaime AC, Bonner K, McGowan KL, Schut L, Sutton LN, Plotkin S. Distribution of bacteria in the operating room environment and its relation to ventricular shunt infections: a prospective study. Childs Nerv Syst 1991;7:211-4.

43. Bayston R, Lari J. A study of the sources of infection in colonised shunts. Dev Med Child Neurol 1974;16 Suppl 32:16-22.

44. Tulipan N, Cleves MA. Effect of an intraoperative doublegloving strategy on the incidence of cerebrospinal fluid shunt infection. J Neurosurg 2006;104 Suppl:5-8. 